\title{
First record of the genus Dinotrema Foerster, 1862 (Hymenoptera, Braconidae, Alysiinae) from the Neotropical region, with description of four new species and a key to the New World taxa
}

\author{
Francisco Javier PERIS-FELIPO ${ }^{1, *}$ \& Sergey A. BELOKOBYLSKIJ ${ }^{2}$ \\ ${ }^{1}$ Bleichestrasse 15, 4058 Basel, Switzerland. \\ ${ }^{2}$ Zoological Institute Russian Academy of Sciences, St. Petersburg, 199034, Russia; \\ Museum and Institute of Zoology Polish Academy of Sciences, Wilcza 64, Warszawa 00-679, Poland. \\ *Corresponding author: peris.felipo@gmail.com \\ ${ }^{2}$ E-Mail: doryctes@gmail.com \\ ${ }^{1}$ urn:Isid:zoobank.org:author:C7B698F7-0A6A-4C4A-915F-8D5ACC380853 \\ ${ }^{2}$ urn:lsid:zoobank.org:author:13EDEDEF-68BA-430B-8FC3-0096874859AB
}

\begin{abstract}
The present work provides the first record of the genus Dinotrema Foerster, 1862 in the Neotropical region. Four new Neotropical species are described and illustrated: D. multiareolatum Peris-Felipo sp. nov., D. plaumanni Peris-Felipo sp. nov., D. subbidentatum Peris-Felipo sp. nov., and $D$. teutoniaense Peris-Felipo sp. nov. The following new combinations are suggested for Nearctic species: Dinotrema angusticornis (Fischer, 1969) comb. nov., D. armillariae (Fischer, 1969) comb. nov., D. bucculatricis (Fischer, 1969) comb. nov., D. caudatulum (Fischer, 1969) comb. nov., D. clayensis (Fischer, 1969) comb. nov., D. communis (Fischer, 1969) comb. nov., D. disstriae (Fischer,1969) comb. nov., D. pauperum (Fischer, 1969) comb. nov., D. saileri (Fischer, 1969) comb. nov., D. shannoni (Fischer, 1969) comb. nov. and D. sylvaticae (Fischer, 1969) comb. nov. An identification key of the all New World Dinotrema species is provided.
\end{abstract}

Key words. Braconidae, Alysiinae, Dinotrema, Nearctic region, Neotropical region.

Peris-Felipo F.J. \& Belokobylskij S.A. 2016. First record of the genus Dinotrema Foerster, 1862 (Hymenoptera, Braconidae, Alysiinae) from the Neotropical region with description of four new species and a key to the New World taxa. European Journal of Taxonomy 179: 1-23. http://dx.doi.org/10.5852/ejt.2016.179

\section{Introduction}

Dinotrema Foerster, 1862 is one of the largest genera in the tribe Alysiini (Braconidae, Alysiinae). Its species are parasitoids of the larvae of Diptera predominantly belonging to the family Phoridae (van Achterberg 1988).

Van Achterberg (1988) provided the current definition of the genus Dinotrema with its species differing from those of the related genus Aspilota Foerster, 1862 by the short size of the paraclypeal fovea far separated from the inner margin of the eye. Moreover, this genus can be differentiated from the genera 
Synaldis Foerster, 1862 by the presence of the vein cuqu1 (2-SR) (Fischer 2003; Tobias 2003, 2004a, 2006) and Adelphenaldis Fischer, 2003 by the short size of the paraclypeal fovea and the presence of the vein cuqu1 (2-SR) (Fischer 2003; Peris-Felipo et al. 2012, 2014a). Recently, Peris-Felipo et al. (2014b) revised the genus Dinotrema of the Western Palaearctic and included its 174 known species in a modern key.

Dinotrema comprises a large number of species described from Afrotropical, Australasian, Nearctic, Oceanic, Oriental and Palaearctic (mainly from Western Europe) regions (Fischer 1972; van Achterberg 1988; Tobias 2003, 2004a, 2004b, 2006; Yu et al. 2012; Peris-Felipo \& Belokobylskij 2013; Peris-Felipo et al. 2013a, 2013b, 2013c, 2013d, 2014b, 2014c). This genus, however, has not yet been reported from the Neotropical region.

In this paper, the genus Dinotrema is recorded for the first time from the Neotropical region with the description and illustration of four new species, D. multiareolatum Peris-Felipo sp. nov., D. plaumanni Peris-Felipo sp. nov., D. subbidentatum Peris-Felipo sp. nov. and D. teutoniaense Peris-Felipo sp. nov.

\section{Material and methods}

For the terminology of the morphological features, sculpture and measurements, see Peris-Felipo et al. (2014b); for wing venation nomenclature, see Peris-Felipo et al. (2014b) and in parenthesis van Achterberg (1993). Also, the morphological groups based on the propodeum sculpture (Peris-Felipo et al. 2014b) are used for the key of the Nearctic and Neotropical Dinotrema species. The material was imaged using a Digital Keyence ${ }^{\circledR}$ VHX-2000 and Adobe Photoshop ${ }^{\circledR}$ imaging system. The types of the described species are deposited in the collection of the Natural History Museum (London, UK; BMNH) and the Zoological Institute of the Russian Academy of Sciences (St Petersburg, Russia; ZISP).

\section{Taxonomic part}

Four new Neotropical species of the genus Dinotrema are described and illustrated: D. multiareolatum sp. nov., D. plaumanni sp. nov., D. subbidentatum sp. nov. and $D$. teutoniaense sp. nov. The type material of the Nearctic species deposited in Naturhistorisches Museum Wien (Austria) was revised and the following taxa are transferred to Dinotrema: D. angusticorne (Fischer, 1969) comb. nov.; D. armillariae (Fischer, 1969) comb. nov.; D. bucculatricis (Fischer, 1969) comb. nov.; D. caudatulum (Fischer, 1969) comb. nov.; D. clayensis (Fischer, 1969) comb. nov.; D. communis (Fischer, 1969) comb. nov.; D. disstriae (Fischer, 1969) comb. nov.; D. pauperum (Fischer, 1969) comb. nov.; D. saileri (Fischer, 1969) comb. nov.; D. shannoni (Fischer, 1969) comb. nov. and D. sylvaticae (Fischer, 1969) comb. nov. Original combinations and publications are listed in Table 1.

A brief key for determination of upper discussed genera is following:

1. Vein cuqu1 (2-SR) of fore wing present

- Vein cuqu1 (2-SR) of fore wing absent

2. Paraclypeal fovea large, reaching margin of eye Aspilota Foerster, 1862

- Paraclypeal fovea short, not reaching margin of eye Dinotrema Foerster, 1862

3. Paraclypeal fovea large, reaching margin of eye Adelphenaldis Fischer, 2003

- Paraclypeal fovea short, not reaching margin of eye Synaldis Foerster, 1862 
Table 1. List of new combinations presented in this paper, with their original name and publication.

\begin{tabular}{|c|c|c|}
\hline $\begin{array}{c}\text { Nearctic species in original } \\
\text { combination }\end{array}$ & $\begin{array}{c}\text { Nearctic species in new } \\
\text { combination }\end{array}$ & $\begin{array}{c}\text { Original } \\
\text { publication }\end{array}$ \\
\hline $\begin{array}{l}\text { Aspilota angusticornis } \\
\text { Fischer, } 1969\end{array}$ & $\begin{array}{l}\text { Dinotrema angusticorne } \\
\text { (Fischer, 1969) }\end{array}$ & Fischer 1969a \\
\hline $\begin{array}{l}\text { Aspilota armillariae } \\
\text { Fischer, } 1969\end{array}$ & $\begin{array}{l}\text { Dinotrema armillariae } \\
\text { (Fischer, 1969) }\end{array}$ & Fischer 1969b \\
\hline $\begin{array}{l}\text { Aspilota bucculatricis } \\
\text { Fischer, } 1969\end{array}$ & $\begin{array}{l}\text { Dinotrema bucculatricis } \\
\text { (Fischer, 1969) }\end{array}$ & Fischer 1969c \\
\hline $\begin{array}{l}\text { Aspilota caudatula } \\
\text { Fischer, } 1969\end{array}$ & $\begin{array}{l}\text { Dinotrema caudatulum } \\
\text { (Fischer, 1969) }\end{array}$ & Fischer 1969d \\
\hline $\begin{array}{l}\text { Aspilota clayensis } \\
\text { Fischer, } 1969\end{array}$ & $\begin{array}{l}\text { Dinotrema clayensis } \\
\text { (Fischer, 1969) }\end{array}$ & Fischer 1969a \\
\hline $\begin{array}{l}\text { Aspilota communis } \\
\text { Fischer, } 1969\end{array}$ & $\begin{array}{l}\text { Dinotrema communis } \\
\text { (Fischer, 1969) }\end{array}$ & Fischer 1969d \\
\hline $\begin{array}{l}\text { Aspilota disstriae } \\
\text { Fischer, } 1969\end{array}$ & $\begin{array}{l}\text { Dinotrema disstriae } \\
\text { (Fischer, 1969) }\end{array}$ & Fischer 1969a \\
\hline $\begin{array}{l}\text { Aspilota paupera } \\
\text { Fischer, } 1969\end{array}$ & $\begin{array}{l}\text { Dinotrema pauperum } \\
\text { (Fischer, 1969) }\end{array}$ & Fischer 1969a \\
\hline $\begin{array}{l}\text { Aspilota saileri } \\
\text { Fischer, } 1969\end{array}$ & $\begin{array}{l}\text { Dinotrema saileri } \\
\text { (Fischer, 1969) }\end{array}$ & Fischer 1969b \\
\hline $\begin{array}{l}\text { Aspilota shannoni } \\
\text { Fischer, } 1969\end{array}$ & $\begin{array}{l}\text { Dinotrema shannoni } \\
\text { (Fischer, 1969) }\end{array}$ & Fischer 1969c \\
\hline $\begin{array}{l}\text { Aspilota sylvaticae } \\
\text { Fischer, } 1969\end{array}$ & $\begin{array}{l}\text { Dinotrema sylvaticae } \\
\text { (Fischer, 1969) }\end{array}$ & Fischer 1969d \\
\hline
\end{tabular}

Class Hexapoda Blainville, 1816

Order Hymenoptera Linnaeus, 1758

Suborder Apocrita Latreille, 1810

Superfamily Ichneumonoidea Latreille, 1802

Family Braconidae Nees, 1811

Subfamily Alysiinae Leach, 1815

Tribe Alysiini Leach, 1815

Genus Dinotrema Foerster, 1862

Type species: Dinotrema erythropa Foerster, 1862.

\section{Diagnosis}

Mandibles small, simple, tridentate. Paraclypeal fovea short, not reaching ventral edge of eyes. Vein cuqu1 (2-SR) present and sclerotized; Nervulus (cu-a) postfurcal. 
Hosts: Dipterans larvae mainly from families Anthomyiidae, Phoridae and Platypezidae.

Dinotrema multiareolatum Peris-Felipo sp. nov.

urn:1sid:zoobank.org:act:682105B3-80C4-4E91-A1B7-1F20FBE132AE

Figs 1-2

\section{Etymology}

Named "multiareolatum" because of the high number of small areolae on the propodeum.

\section{Type material}

Holotype

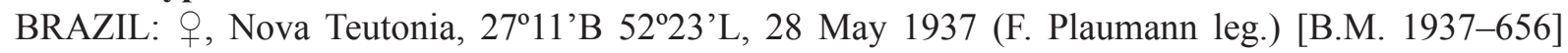
(BNHM).

\section{Paratypes}

BRAZIL: 23 우, same label as holotype, but Aug. 1935, 16 Sep. 1935, Oct. 1935, Nov. 1935, 8 Mar. 1936, Feb. 1937, 28 May 1937, 12 Jun. 1937, 14 Jun. 1937, 15 Jun. 1937, 16 Jun. 1937, 10 Jul. 1937, 26 Jul. 1937 [B.M. 1937-656], 16 Aug. 1938 [B.M. 1938-682], 7 Oct. 1938 [B.M. 1938-312]; 6 ふ઼ ô, same label as holotype, but 4 Jun. 1937, 11 Jun. 1937, 4 Aug. 1937, 13 Apr. 1938 [B.M. 1938-682] (BNHM, ZISP); 1 +, Argentina, Misiones Province, Iguazu Nat. Park., ca. 140 m, 8-11 Apr. 1974, Malaise trap (C. \& M. Vardy) [B.M. 1974-204] (BNHM).

\section{Description}

\section{Female}

HeAD. In dorsal view 1.6 times as wide as long, 1.5 times as wide as mesoscutum, smooth, with temple rounded behind eyes. Eye in lateral view 1.6 times higher than wide and 1.5 times as wide as temple medially. POL 1.1 times as long as OD; OOL 2.6 times OD. Face 1.9 times as wide as high, completely covered by numerous setae; inner margins of eyes subparallel. Clypeus 2.3 times as wide as high, slightly curved ventrally. Paraclypeal fovea short, reaching halfway distance between clypeus and eye. Mandible 3-dentate, slightly widened towards apex, 1.7 times as long as its maximum width. Upper tooth small, shorter than lower and middle teeth; middle tooth small, slightly longer than upper tooth, wide basally and pointed apically; lower tooth short, wide, rounded. Antennae 23-segmented, 1.1 times longer than body. Scape 1.9 times as long as pedicel. First flagellar segment 3.8 times as long as its apical width, 1.3 times as long as second segment. Second to thirteenth flagellar segments 2.2-2.5 times as long as their maximum width; $14^{\text {th }}$ to $20^{\text {th }}$ segments about 2.0 times, and $21^{\text {st }}$ (apical) segment 2.5 times as long as wide.

Mesosoma. In lateral view 1.3 times as long as high. Mesoscutum (in dorsal view) 0.9 times as long as its maximum width, with numerous setae situated on middle part of mesoscutum. Notauli mainly absent on horizontal surface of mesoscutum. Mesoscutal pit present and elongate. Prescutellar depression smooth, without lateral carinae. Precoxal sulcus present, crenulate, not reaching anterior and/or posterior margins of mesopleuron. Posterior mesopleural furrow smooth. Propodeum sculptured, with complete and distinct median longitudinal carina and with transversal carinae reaching sides of propodeum. Propodeal spiracles relatively small.

WINGS. Length of fore wing 2.6 times its maximum width. Radial (marginal) cell ending at apex of wing, 3.8 times as long as its maximum width. Vein cuqu1 (2-SR) present and sclerotized. Vein r2 (3-SR) 2.1 times as long as vein cuqu1 (2-SR); vein r3 (SR1) 2.8 times as long as vein r2 (3-SR). Nervulus (cu-a) distinctly postfurcal. Brachial (subdiscal) cell closed distally, 3.6 times as long as its maximum width. Hind wing 5.5 times as long as its maximum width. 
Legs. Hind femur 4.4 times as long as its maximum width. Hind tibia slightly widened apically, 9.4 times as long as its maximum subapical width and as long as hind tarsus. First segment of hind tarsus 1.8 times as long as second segment.

Metasoma. First tergite slightly widened towards apex, 3.1 times as long as its apical width, entirely striate. Ovipositor 1.2 times as long as first tergite, 0.6 times as long as metasoma, 1.7 times as long as hind femur.
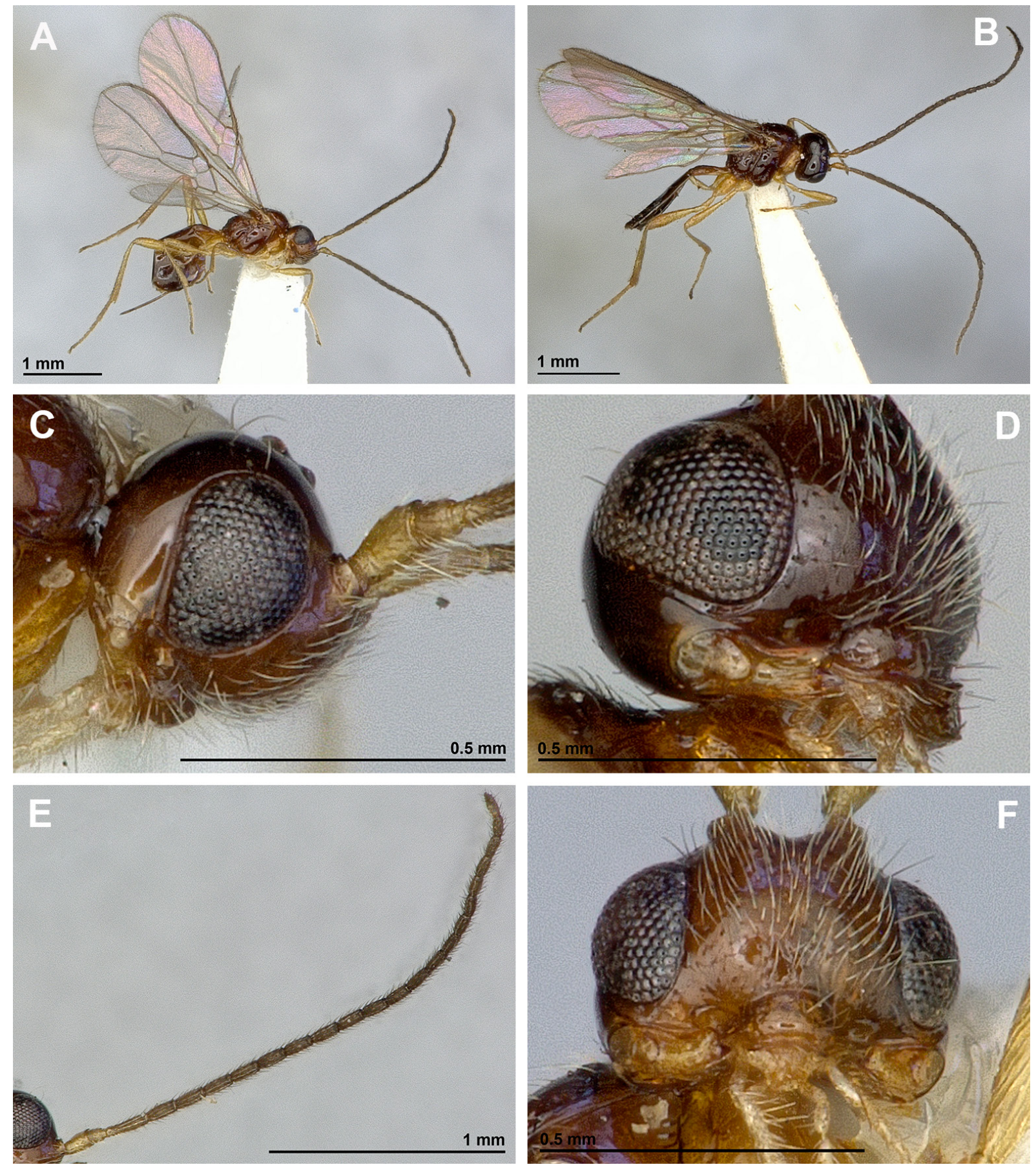

Fig. 1. Dinotrema multiareolatum Peris-Felipo sp. nov. (A, C-F $\odot$; B §̊). A-B. Habitus, lateral view. C. Head, lateral view. D. Mandible. E. Antenna. F. Face, frontal view. 
CoLour. Body, flagellar segments and pterostigma brown. Legs yellow, scape and pedicel brownish yellow. Wings hyaline.

Length. Body $1.6 \mathrm{~mm}$; fore wing $2.1 \mathrm{~mm}$; hind wing $1.3 \mathrm{~mm}$.
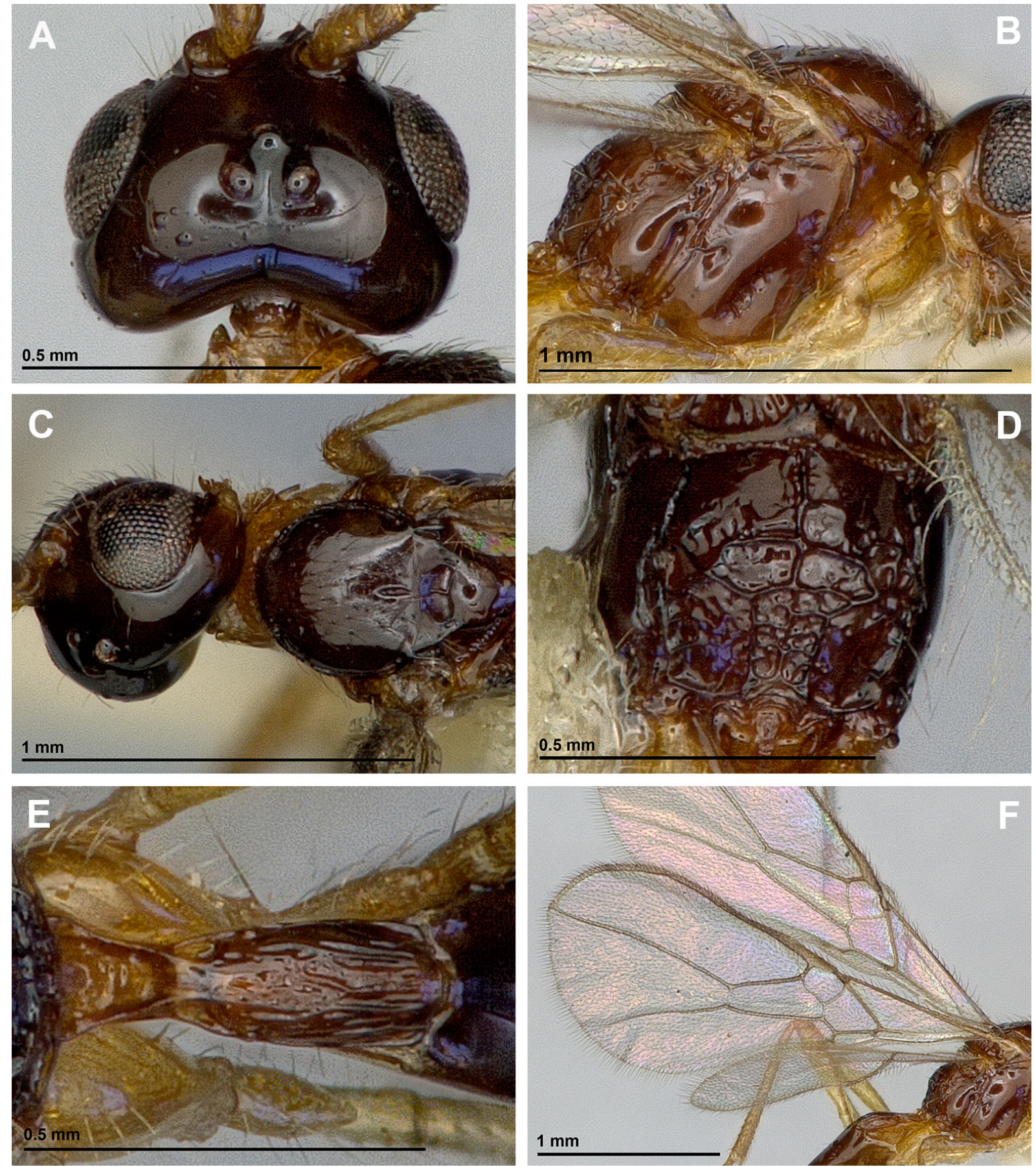

Fig. 2. Dinotrema multiareolatum Peris-Felipo sp. nov. (). A. Head, dorsal view. B. Mesosoma, lateral view. C. Head, sublateral view and mesonotum, dorsal view. D. Propodeum, dorsal view. E. First metasomal tergite. F. Fore and hind wings. 
VARIATION. Body 1.5-1.7 mm; fore wing 2.0-2.2 mm; hind wing 1.3-1.5 mm. Antenna 22-24-segmented. Hind femur 4.4-4.5 times as long as its maximum width.

\section{Male}

Body length $2.0 \mathrm{~mm}$; fore wing $2.3 \mathrm{~mm}$; hind wing $1.5 \mathrm{~mm}$. Antenna 27-28-segmented. First flagellar segment 4.0 times as long as its maximum width.

\section{Comparative diagnosis}

This new species is similar to Dinotrema caudatulum (Fischer, 1969), D. communis (Fischer, 1969) and D. sylvaticae (Fischer, 1969). Dinotrema multiareolatum sp. nov. differs from D. caudatulum in having the mandible 1.7 times as long as its maximum width (1.0 times in D. caudatulum), the first flagellar segment 3.8 times as long as its maximum width (3.0 times in D. caudatulum), hind femur 4.4 times as long as its maximum width (3.5 times in $D$. caudatulum), the first metasomal tergite 3.1 times as long as its apical width (1.5 times in $D$. caudatulum $)$. On the other hand, D. multiareolatum sp. nov. differs from D. communis in having the mandible 1.7 times as long as its maximum width (1.3 times in D. communis), the first flagellar segment 3.8 times as long as its maximum width (3.0 times in D. communis), hind femur 4.4 times as long as its maximum width (3.9 times in D. communis), and the first metasomal tergite 3.1 times as long as its apical width (1.8 times in D. communis). Finally, D. multiareolatum sp. nov. differs from $D$. sylvaticae in having the mandible 1.7 times as long as its maximum length (1.2 times in D. sylvaticae), posterior mesopleural furrow smooth (crenulate in D. sylvaticae), hind femur 4.4 times as long as its maximum width (3.6 times in D. sylvaticae), and the first metasomal tergite 3.1 times as long as its apical width (2.0 times in D. sylvaticae).

According to the key by Peris-Felipo et al. (2014b), this new species is similar to the Palaearctic D. oleraceum (Tobias, 1962) and D. paludellae Munk \& Peris-Felipo, 2013. Dinotrema multiareolatum sp. nov. differs from $D$. oleraceum in having the mandible 1.7 times as long as its maximum width (2.0 times in D. oleraceum), the first flagellar segment 3.8-4.0 times as long as its maximum width (3.0 times in D. oleraceum), hind femur 4.4 times as long as its maximum width (4.0 times in D. oleraceum), and the first metasomal tergite 3.1 times as long as its apical width (1.7 times in D. oleraceum). Finally, D. multiareolatum sp. nov. differs from D. paludellae in having the mandible 1.7 times as long as its maximum width (1.85-1.90 times in D. paludellae), the first flagellar segment 3.8-4.0 times as long as its maximum width (2.3-2.4 times in D. paludellae), hind femur 4.4 times as long as its maximum width (3.6-3.7 times in D. paludellae), and the first metasomal tergite 3.1 times as long as its apical width (2.2-2.3 times in D. paludellae).

\section{Dinotrema plaumanni Peris-Felipo sp. nov. urn:1sid:zoobank.org:act:7A99D0C5-C2F8-4401-B364-44E1DD5A0631}

Figs 3-4

\section{Etymology}

Named after Fritz Plaumann who collected the type material of this species.

\section{Type material}

\section{Holotype}

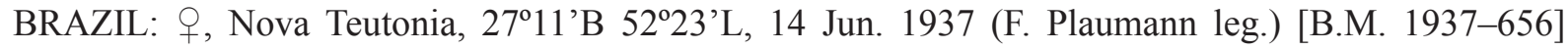
(BNHM).

\section{Paratypes}

1 ㅇ, 1 今ે, same locality as holotype, but 28 Aug. 1937 and 3 Apr. 1938 [B.M. 1938-682] (BNHM). 


\section{Description}

\section{Female}

HEAD. In dorsal view, 1.8 times as wide as long, 1.5 times as wide as mesoscutum, smooth, with temple rounded behind eyes. Eye in lateral view 1.8 times higher than wide and 1.8 times as wide as temple medially. POL as long as OD; OOL 2.5 times OD. Face 1.7 times as wide as high, completely covered
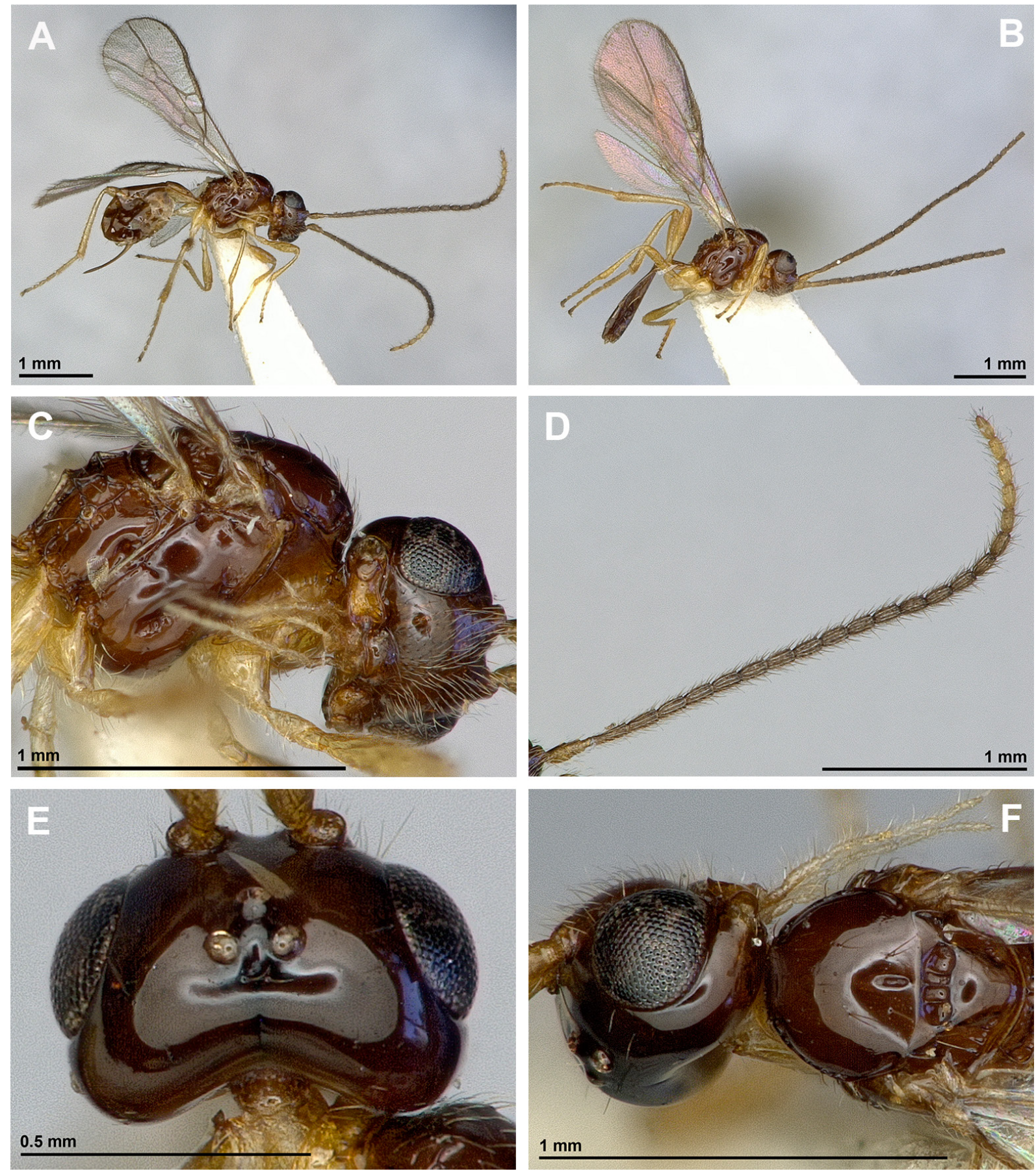

Fig. 3. Dinotrema plaumanni Peris-Felipo sp. nov. (A, C-F $\circ$; B §). A-B. Habitus, lateral view. C. Face, mandible and mesosoma in lateral view. D. Antenna. E. Head, dorsal view. F. Head, lateral view and mesonotum, dorsal view. 
by numerous setae; inner margins of eyes subparallel. Clypeus 2.2 times as wide as high, slightly curved ventrally. Paraclypeal fovea short, not reaching middle of distance between clypeus and eye. Mandible 3-dentate, slightly widened towards apex, 1.3 times as long as its maximum width. Upper tooth small, longer than lower and middle teeth; middle tooth small, slightly longer than upper tooth, wide basally and pointed apically; lower tooth short, rounded. Antennae 23-segmented, 1.2 times longer than body. Scape 1.4 times as long as pedicel. First flagellar segment 3.5 times as long as its apical width, 1.3 times as long as second segment. Second to thirteenth flagellar segments 2.1-2.4 times as long as their maximum width; $14^{\text {th }}$ to $17^{\text {th }}$ segments $1.9-2.1$ times, $18^{\text {th }}$ to $20^{\text {th }}$ segment $1.6-1.8$ times, and $21^{\text {st }}$ (apical) segment 2.3 times as long as wide.

Mesosoma. In lateral view, 1.3 times as long as high. Mesoscutum (dorsal view) 0.8 times as long as its maximum width. Notauli mainly absent on smooth horizontal surface of mesoscutum. Mesoscutal pit present and elongate. Prescutellar depression smooth, with lateral carinae. Precoxal sulcus present, crenulate, not reaching anterior and/or posterior margins of mesopleuron. Posterior mesopleural furrow smooth. Propodeum entirely rugose-reticulate, with pentagonal areola. Propodeal spiracles relatively small.

WiNGS. Length of fore wing 2.5 times its maximum width. Radial (marginal) cell ending at apex of wing, 3.3 times as long as its maximum width. Vein cuqu1 (2-SR) present and sclerotized. Vein r2 (3-SR) 2.2 times as long as vein cuqu1 (2-SR); vein r3 (SR1) 2.0 times as long as vein r2 (3-SR). Nervulus (cu-a)
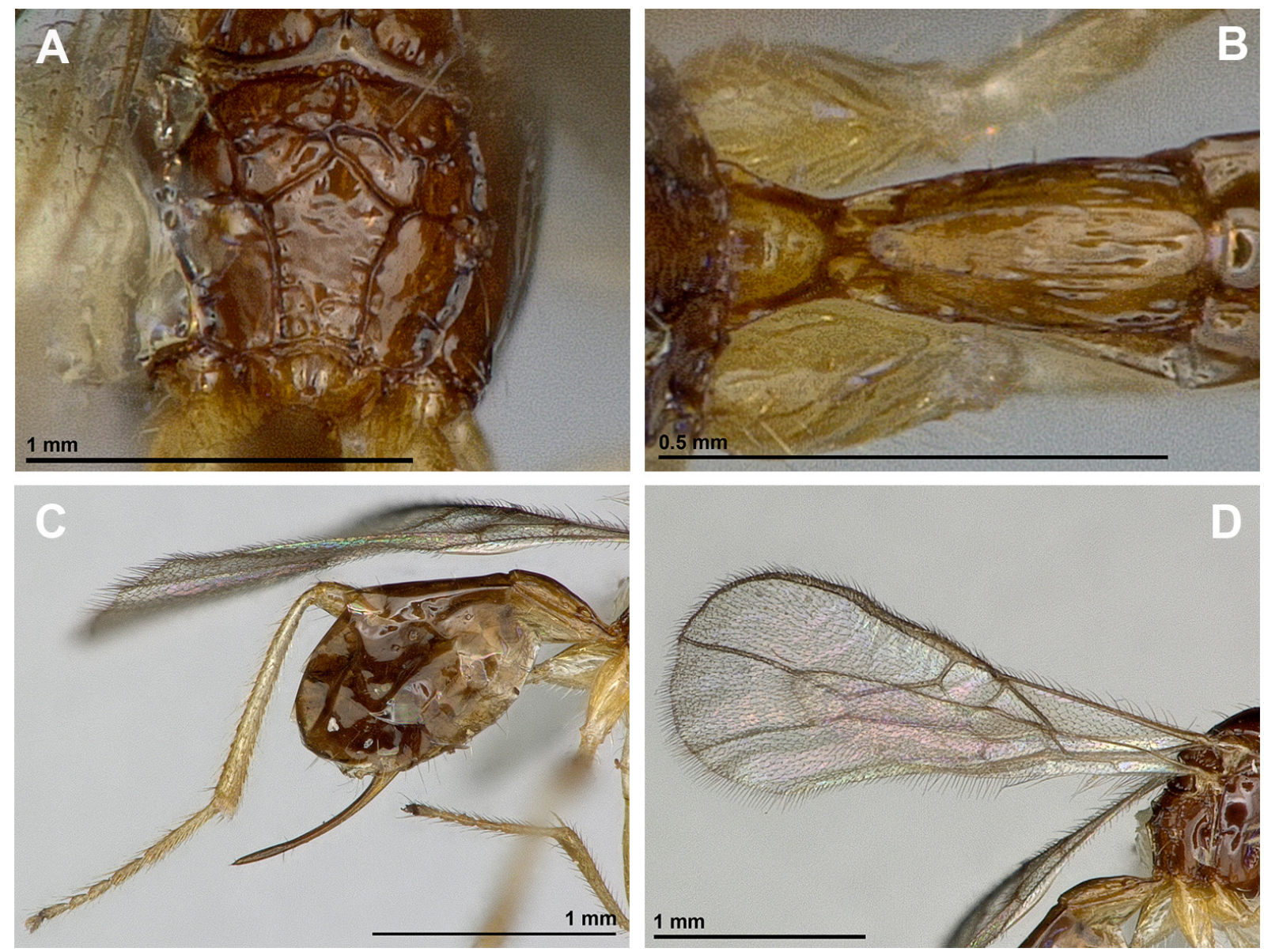

Fig. 4. Dinotrema plaumanni Peris-Felipo sp. nov. (†). A. Propodeum, dorsal view. B. First metasomal tergite. C. Metasoma, hind leg and ovipositor, lateral view. D. Fore and hind wings. 
distinctly postfurcal. Brachial (subdiscal) cell closed distally, 3.9 times as long as its maximum width. Hind wing 5.5 times as long as its maximum width.

Legs. Hind femur 3.8 times as long as its maximum width. Hind tibia slightly widened apically, 9.1 times as long as its maximum subapical width, 1.1 times as long as hind tarsus. First segment of hind tarsus 2.2 times as long as second segment.

Metasoma. First tergite slightly widened towards apex, 3.0 times as long as its apical width, striate. Ovipositor 1.7 times as long as first tergite, 0.6 times as long as metasoma and 1.1 times as long as hind femur.

CoLour. Body, antenna and pterostigma brown. Legs yellowish brown. Last five apical flagellar segments paler than middle segments, yellowish brown. Wings hyaline.

Length. Body $2.0 \mathrm{~mm}$; fore wing $2.4 \mathrm{~mm}$; hind wing $1.7 \mathrm{~mm}$.

VARIATION. Hind femur 3.9 times as long as its maximum width.

\section{Male}

Body $2.2 \mathrm{~mm}$; fore wing $2.0 \mathrm{~mm}$; hind wing $1.5 \mathrm{~mm}$. Antenna more than 22 -segmented (apical segments missing). Hind femur 4.2 times as long as its maximum width.

\section{Comparative diagnosis}

This new species is similar to Dinotrema subbidentatum sp. nov. but differs from it in having a rather long (visible in lateral view) upper tooth of mandible (very short and almost invisible in D. subbidentatum sp. nov.), mandible 1.3 times as long as its maximum width (1.7 times in D. subbidentatum sp. nov.), apical flagellar segments paler than middle segments (apical and middle segments similarly coloured in D. subbidentatum sp. nov.), the first flagellar segment 3.5 times as long as its maximum width (2.5-3.0 times in D. subbidentatum sp. nov.), eye in lateral view 1.8 times as wide as temple medially (1.3 times in D. subbidentatum sp. nov.), and the first metasomal tergite 3.0 times as long as its apical width (1.4 times in D. subbidentatum sp. nov.).

According to the key by Peris-Felipo et al. (2014b), this new species is similar to Dinotrema adventum (Fischer, 1973) and D. macrocera (Thomson, 1895). Dinotrema plaumanni sp. nov. differs from these species in having the first metasomal tergite 3.0 times as long as its apical width (2.0 times in $D$. adventum and 2.2 times in D. macrocera), face 1.7 times as wide as high (1.25 times in D. adventum and 1.5 times in D. macrocera), mesoscutal pit elongate (rounded in D. adventum and oval in D. macrocera), and prescutellar depression with lateral carinae (without lateral carinae in D. adventum and D. macrocera).

Dinotrema subbidentatum Peris-Felipo sp. nov. urn:1sid:zoobank.org:act:367E3A7F-8D21-4882-9499-B42A909C84B2

Figs $5-7$

\section{Etymology}

Named derived from the allusion of having only two teeth at the mandible in lateral view.

\section{Type material}

Holotype

BRAZIL: + , Sta. Cat., Nova Teutonia, 27 Jul. 1952 (F. Plaumann leg.) [B.M. 1957-341] (BNHM). 


\section{Paratypes}

BRAZIL: 1 ㅇ, same locality as holotype, but $27^{\circ} 11^{\prime}$ B 52 $23^{\prime}$ 'L, 7 Jun. 1937 (F. Plaumann leg.) [B.M. 1937-656] (BNHM); 7 우, $5 \widehat{\widehat{\partial}}$, same locality as holotype, but 29 May 1937, 19 Aug. 1937 [B.M. 1937-748], 30 Apr. 1938, 10 May 1938, 16 Jun. 1935, 25 Aug. 1935, 10 Sep. 1935, 8 Mar. 1936; 1 ठ, same locality as holotype, but $27^{\circ} \mathrm{B} 52-58^{\circ} \mathrm{L}, 3$ Jun. 1938 (F. Plaumann leg.) [B.M. 1938-458] (BNHM,
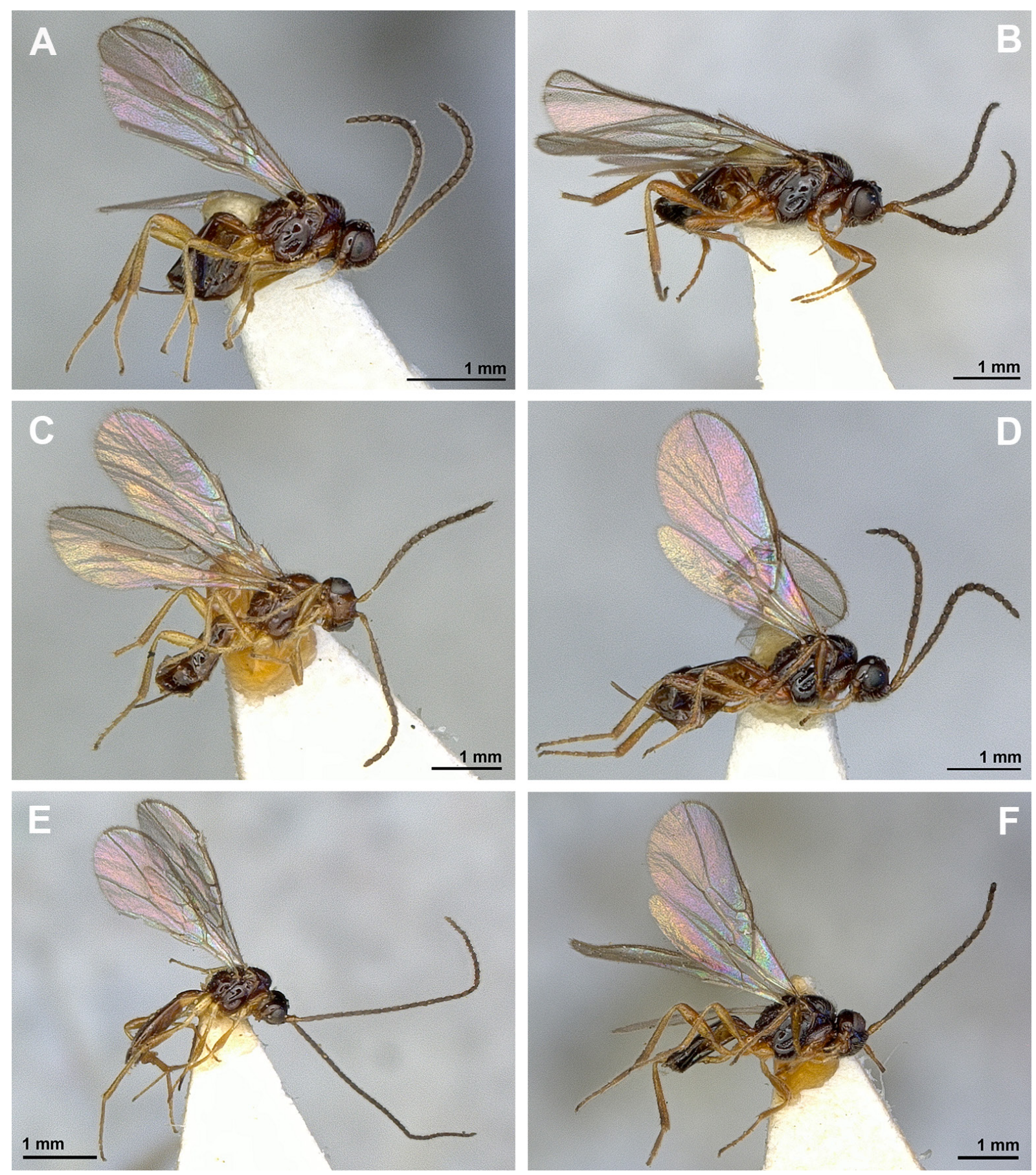

Fig. 5. Dinotrema subbidentatum Peris-Felipo sp. nov. (A-D + ; E-F § ). A. Habitus variety body light - metasoma short, lateral view. B. Habitus variety body dark - metasoma short, lateral view. C. Habitus variety body light - metasoma long, lateral view. D. Habitus variety body dark - metasoma long, lateral view. E. Habitus variety body light, lateral view. F. Habitus variety body dark, lateral view. 
ZISP); 55 우, 1 đે, same locality, but 24 Mar. 1941 [B.M. 1957-341], 12 Aug. 1941, 9 Nov. 1941, 12 Sep. 1941, 14 Jul. 1944, 17 Jul. 1944, 23 Jul. 1945, 19 Apr. 1952, 10 May 1952, 30 May 1952, 1 Jun. 1952, 2 Jun. 1952, 3 Jun. 1952, 5 Jun. 1952, 17 Jul. 1952, 27 Jul. 1952, 2 Aug. 1952, 23 Oct. 1952, 26 Sep. 1952 (BNHM, ZISP); 1 q, Paraná, Rondon, Jul. 1952 (F. Plaumann leg.) [B.M. 1957-341] (BNHM).

\section{Description}

\section{Female}

HEAD. In dorsal view twice as wide as long, 1.5 times as wide as mesoscutum, smooth, with temple rounded behind eyes. Eye in lateral view 1.6 times higher than wide and 1.3 times as wide as temple medially. POL 1.2 times as long as OD; OOL 2.3 times OD. Face 1.8 times as wide as high, completely covered by numerous setae; inner margins of eyes subparallel. Clypeus 3.4 times as wide as high, slightly curved ventrally. Paraclypeal fovea short, reaching middle of distance between clypeus and eye. Mandible 3-dentate, but in lateral view only two teeth visible, slightly widened towards apex, 1.7 times as long as its maximum width. Upper tooth not visible in lateral view, very small, shorter than lower and middle teeth; middle tooth small, slightly longer than upper tooth, wide basally and pointed apically; lower tooth short, wide, rounded. Antennae 17-segmented, about as long as body. Scape 1.7 times as long as pedicel. First flagellar segment 2.5 times as long as its apical width, 1.3 times as long as second segment; second segment 1.1 times as long as its maximum width. Third to thirteenth flagellar segments $1.3-1.5$ times, $14^{\text {th }}$ segment 1.8 times, and $15^{\text {th }}$ (apical) segment 2.0 times as long as their width.

Mesosoma. In lateral view, 1.2 times as long as high. Mesoscutum (dorsal view) as long as its maximum width, with numerous setae located on its middle part. Notauli mainly absent on horizontal surface of mesoscutum. Mesoscutal pit distinct and elongate. Prescutellar depression smooth, with median and lateral carinae. Precoxal sulcus present, crenulate, not reaching anterior and posterior margins of mesopleuron. Posterior mesopleural furrow smooth. Propodeum mainly smooth, with pentagonal areola. Propodeal spiracles relatively small.

WINGS. Length of fore wing 2.5 times its maximum width. Radial (marginal) cell ending at apex of wing, 4.0 times as long as its maximum width. Vein cuqu1 (2-SR) sclerotized. Vein r2 (3-SR) 1.8 times as long as vein cuqu1 (2-SR); vein r3 (SR1) 2.6 times as long as vein r2 (3-SR). Nervulus (cu-a) distinctly postfurcal. Brachial (subdiscal) cell closed distally, 3.0 times as long as its maximum width. Hind wing 5.6 times as long as its maximum width.

Legs. Hind femur 3.9 times as long as its maximum width. Hind tibia slightly widened apically, 8.3 times as long as its maximum subapical width and about as long as hind tarsus. First segment of hind tarsus 1.9 times as long as second segment.

Metasoma. First tergite slightly widened towards apex, 1.4 times as long as its apical width, entirely striate. Ovipositor 1.4 times as long as first tergite, 0.6 times as long as metasoma, 0.9 times as long as hind femur.

CoLour. Body, flagellar segments and pterostigma from brown or dark brown. Legs yellow. Wings hyaline.

LeNGTH. Body $1.6 \mathrm{~mm}$; fore wing $2.2 \mathrm{~mm}$; hind wing $1.6 \mathrm{~mm}$.

\section{Male}

Body length $2.0 \mathrm{~mm}$; fore wing $2.5 \mathrm{~mm}$; hind wing $1.9 \mathrm{~mm}$. Antenna 17-19-segmented. First flagellar segment 3.0 times as long as its maximum width. 
VARIATION. This new species has four morphological groups based on the body colour and the size of metasoma.

Body light - metasoma short (Fig. 5A); this is the typical form.

Body light - metasoma elongated (Fig. 5C, 5E): legs yellow; ovipositor 0.4 times as long as metasoma; body length $1.7 \mathrm{~mm}$; antenna $16-17$-segmented.
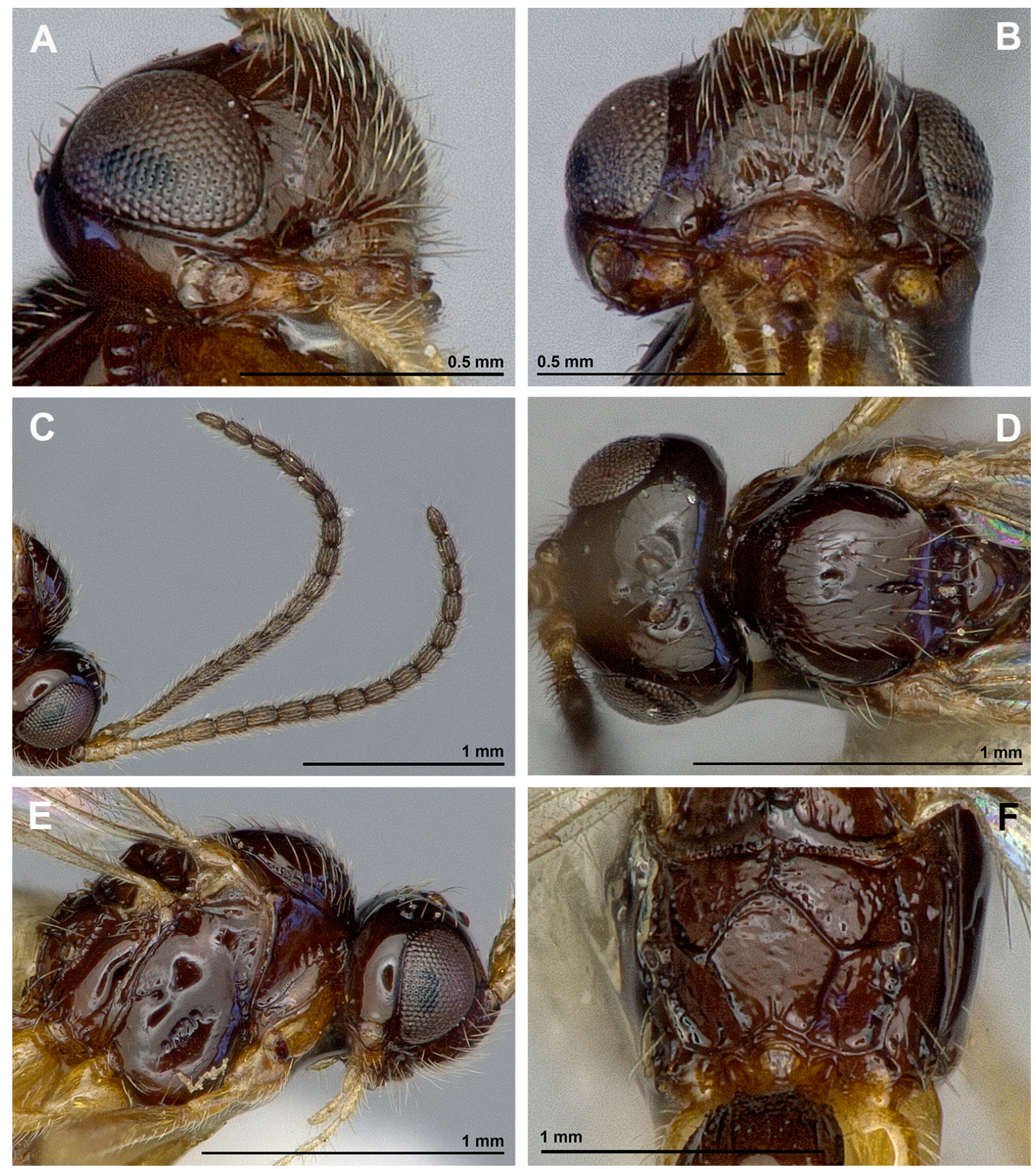

Fig. 6. Dinotrema subbidentatum Peris-Felipo sp. nov. (q). A. Head and mandible, lateral view. B. Face, frontal view. C. Antenna. D. Head and mesonotum, dorsal view. E. Head and mesosoma, lateral view. F. Propodeum, dorsal view. 
Body dark - metasoma short (Fig. 5B, 5F): legs dark brown; ovipositor 0.4 times as long as metasoma; body length $1.9 \mathrm{~mm}$; antenna 16-18-segmented.

Body dark - metasoma elongated (Fig. 5D): legs dark brown; ovipositor 0.45 times as long as metasoma; body length $1.8 \mathrm{~mm}$; antenna 16-18-segmented.

\section{Comparative diagnosis}

This new species is similar to Dinotrema plaumanni sp. nov.; differences between both species are shown after the description of the last species.

According to the key by Peris-Felipo et al. (2014b), this new species is similar to Dinotrema necrophilum (Hedqvist, 1972) and D. varimembre (Fischer, 1973). Dinotrema subbidentatum sp. nov. differs from $D$. necrophilum in having the mandible 1.7 times as long as its maximum width (1.5 times in $D$. necrophilum), the first metasomal tergite 1.4 times as long as its apical width (1.6 times in D. necrophilum), mesoscutal pit elongate (oval in D. necrophilum), and prescutellar depression with lateral carinae (without lateral carinae in D. necrophilum). Also, D. subbidentatum sp. nov. differs from D. varimembre in having the face 1.8 times as wide as high (1.4 times in $D$. varimembre), the first metasomal tergite 1.4 times as long as its apical width (1.8-2.0 times in D. varimembre), mesoscutal pit elongate (oval in D. varimembre), and prescutellar depression with lateral carinae (without lateral carinae in D. varimembre).
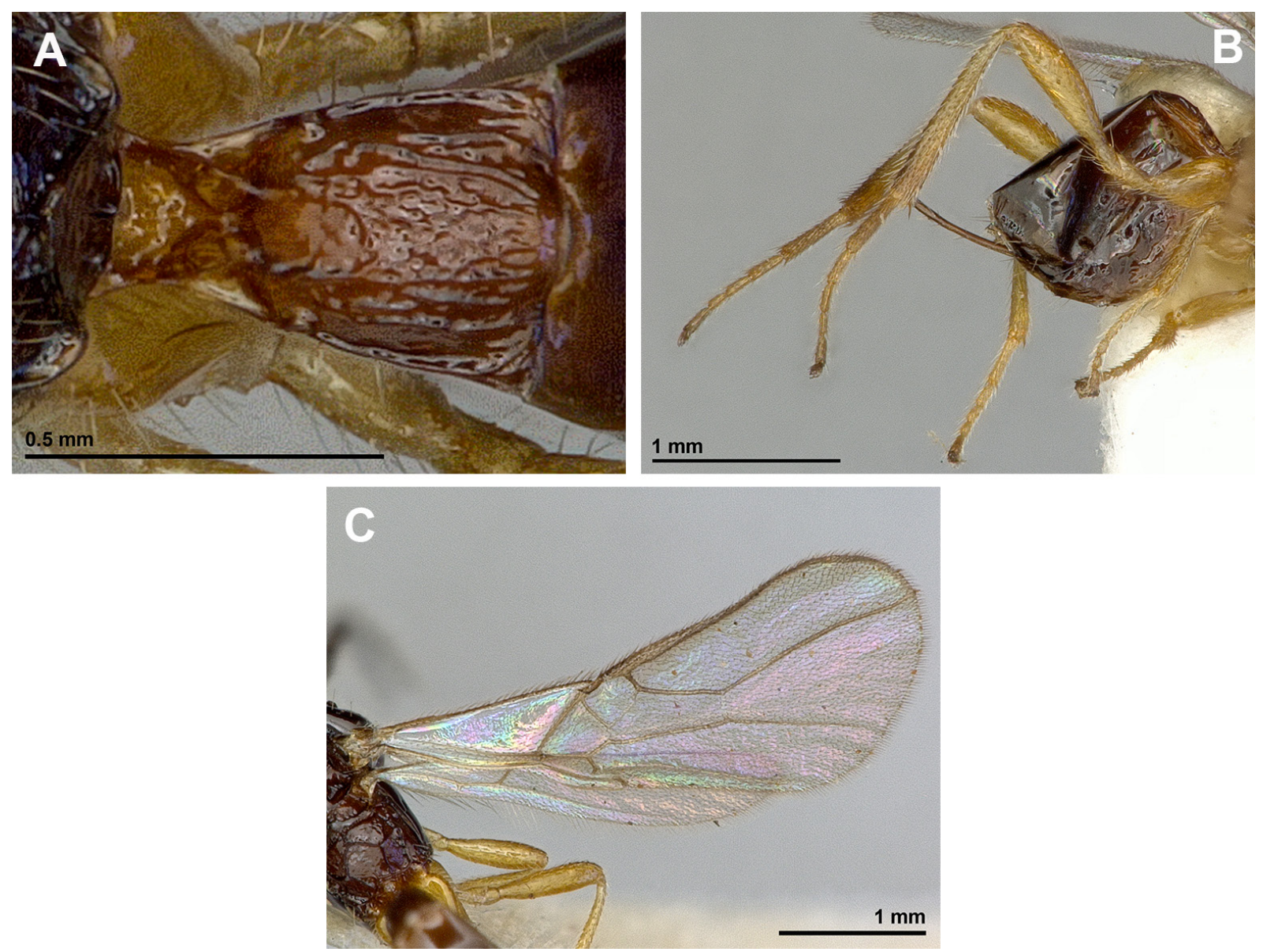

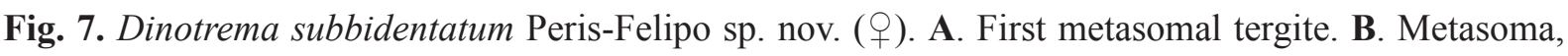
hind leg and ovipositor, lateral view. C. Fore and hind wings. 


\section{Dinotrema teutoniaense Peris-Felipo sp. nov. urn:1sid:zoobank.org:act:EF9D55A8-0FE6-4870-9424-D6C09A3F3E66}

Figs 8-9

\section{Etymology}

Named after Teutônia ("Nova Teutonia"), the type locality of new species.

\section{Type material}

Holotype

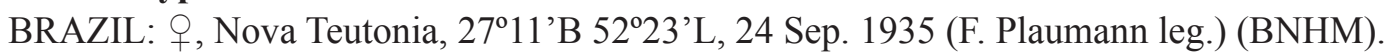

\section{Paratypes}

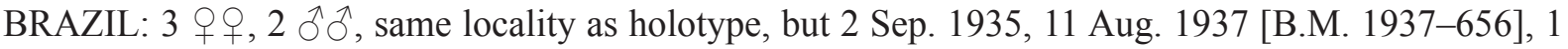
Jun. 1938 [B.M. 1938-458], 24 Apr. 1938, 6 May 1938 [B.M. 1938-682] (BNHM); 1 q, same locality as holotype, but “[B.M. 1957-341]" (ZISP).

\section{Description}

Female

HEAD. In dorsal view, 1.8 times as wide as long, 1.4 times as wide as mesoscutum, smooth, with temple rounded behind eyes. Eye in lateral view 1.3 times higher than wide and 1.5 times as wide as temple medially. POL 1.5 times as long as OD; OOL 5.2 times OD. Face 1.2 times as wide as high, completely covered by numerous setae; inner margins of eyes subparallel. Clypeus 3.1 times as wide as high, slightly curved ventrally. Paraclypeal fovea long, surpassing middle of distance between clypeus and eye but remains distinctly removed from eye. Mandible 3-dentate, in lateral view only two teeth visible, slightly widened towards apex, 1.3 times as long as its maximum width. Upper tooth not visible in lateral view, very small, shorter than lower and middle teeth; middle tooth small, slightly longer than upper tooth, wide basally and pointed apically; lower tooth short, wide, rounded. Antennae 18-segmented, 1.3 times longer than body. Scape 2.5 times as long as pedicel. First flagellar segment 5.5 times as long as its apical width, 1.1 times as long as second segment. Second flagellar segment 4.0 times as long as its maximum width. Third to sixth segments 3.6 times, seventh to eleventh segments 3.2 times; $12^{\text {th }}$ and $13^{\text {th }}$ segments 2.6 times; $14^{\text {th }}$ and $15^{\text {th }}$ segments 3.2 times, and $16^{\text {th }}$ (apical) segment 3.5 times as long as width.

Mesosoma. In lateral view 1.3 times longer than high. Mesoscutum (dorsal view) 0.8 times longer than its maximum width. Notauli mainly absent on smooth horizontal surface of mesoscutum. Mesoscutal pit distinct and rounded. Prescutellar depression smooth, without lateral carinae. Precoxal sulcus present, crenulate, not reaching anterior and posterior margins of mesopleuron. Posterior mesopleural furrow smooth. Propodeum smooth, with complete and distinct median longitudinal carina, with short transverse carinae not reaching sides of propodeum. Propodeal spiracles relatively small.

WINGS. Length of fore wing 2.4 times its maximum width. Radial (marginal) cell ending at apex of wing, 3.5 times as long as its maximum width. Vein cuqu1 (2-SR) present and sclerotized. Vein r2 (3-SR) 3.6 times as long as vein cuqu1 (2-SR); vein r3 (SR1) 2.6 times as long as vein r2 (3-SR). Nervulus (cu-a) distinctly postfurcal. Brachial (subdiscal) cell closed distally, 2.5 times as long as its maximum width. Hind wing 5.9 times as long as its maximum width.

LEgs. Hind femur 5.0 times longer than its maximum width. Hind tibia slightly widened to apex, 10.3 times longer than its maximum subapical width, 1.3 times as long as hind tarsus. First segment of hind tarsus 2.4 times as long as second segment. 
Metasoma. First tergite slightly widened towards apex, 2.8 times as long as its apical width, striate. Ovipositor 1.7 times as long as first tergite, 0.6 times as long as metasoma, about as long as hind femur.

Colour. Body and pterostigma brown. Antenna, side of pronotum and legs yellowish brown. Five apical flagellar segments paler than middle segments, yellowish brown. Wings hyaline.

LENGTH. Body $1.3 \mathrm{~mm}$; fore wing $1.5 \mathrm{~mm}$; hind wing $1.2 \mathrm{~mm}$.
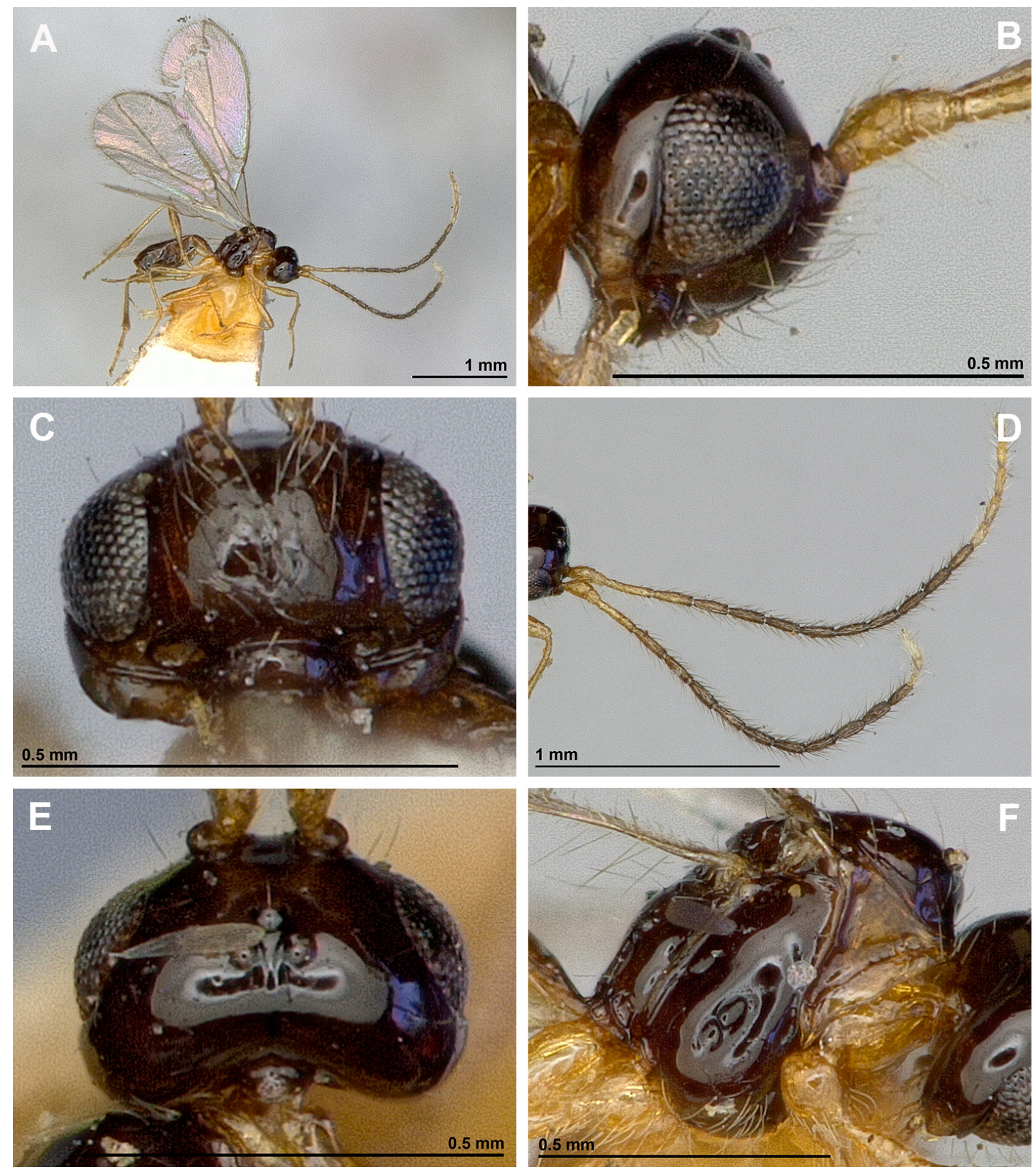

Fig. 8. Dinotrema teutoniaense Peris-Felipo sp. nov. ( + ). A. Habitus, lateral view. B. Head, lateral view. C. Face and mandible, frontal view. D. Antenna. E. Head, dorsal view. F. Mesosoma, lateral view. 
VARIATION. Body length $1.3-1.4 \mathrm{~mm}$; fore wing length $1.5-1.6 \mathrm{~mm}$; hind wing length $1.2-1.3 \mathrm{~mm}$. Antenna 18-19-segmented.

\section{Male}

Body length $1.4 \mathrm{~mm}$; fore wing length $1.5 \mathrm{~mm}$; hind wing length $1.2 \mathrm{~mm}$. Antenna 19-segmented.
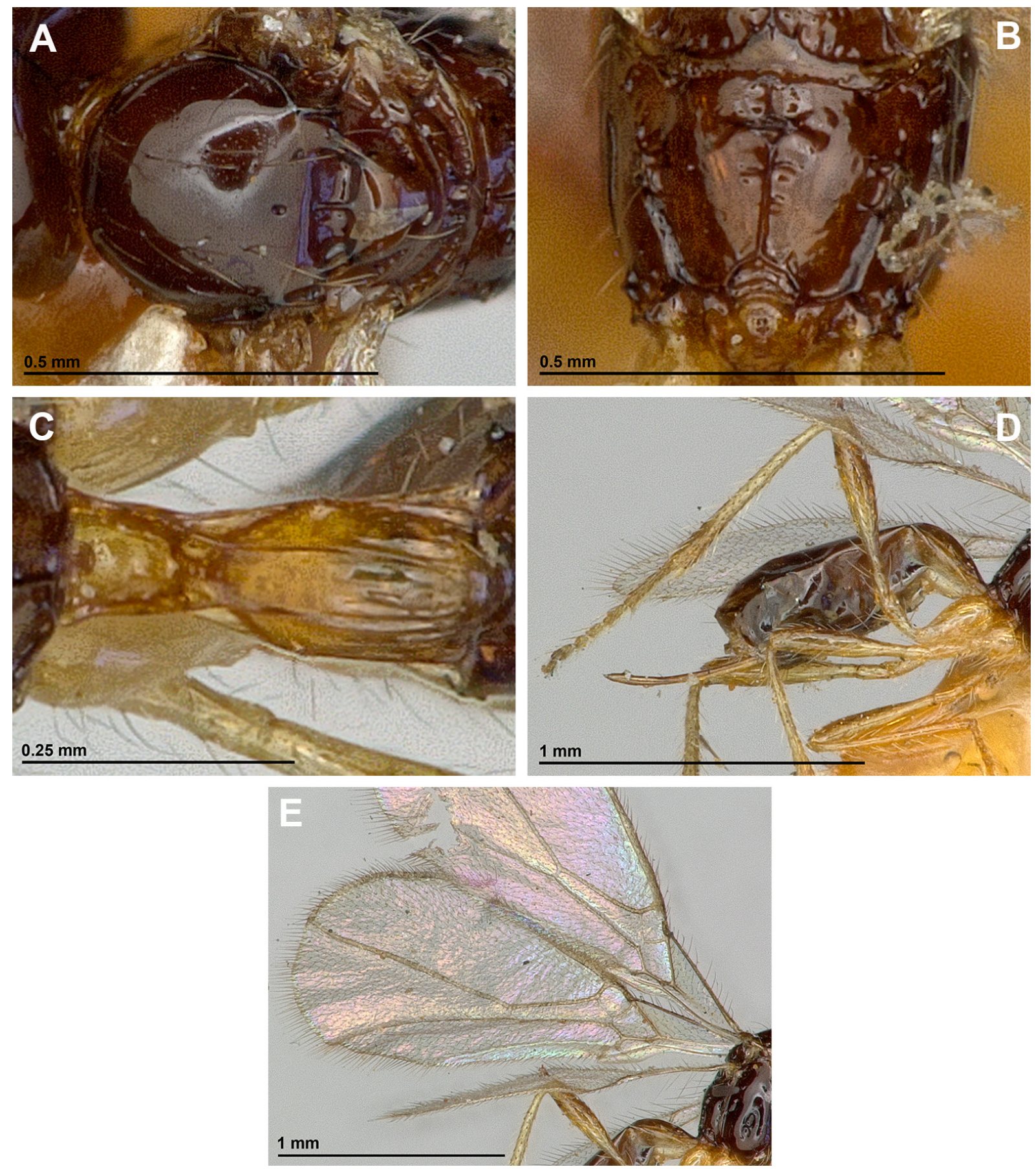

Fig. 9. Dinotrema teutoniaense Peris-Felipo sp. nov. (†). A. Mesonotum, dorsal view. B. Propodeum, dorsal view. C. First metasomal tergite. D. Metasoma, hind leg and ovipositor, lateral view. E. Fore and hind wings. 


\section{Comparative diagnosis}

This new species is similar to D. angusticorne (Fischer, 1969a) and D. disstrae (Fischer, 1969a). Dinotrema teutoniaense sp. nov. differs from these species in having the mandible 2.0 times as long as its maximum width (1.3 times in D. angusticorne and 1.7 times in $D$. disstrae), the first flagellar segment 5.5 times as long as its maximum width (3.8 times in D. angusticorne and 2.2 times in D. disstrae), hind femur 5.0 times as long as its maximum width (4.3 times in D. angusticorne and D. disstrae), and the first metasomal tergite 2.8 times as long as its apical width (2.0 times in D. angusticorne and 1.8 times in D. disstrae).

According to the key by Peris-Felipo et al. (2014b), this new species is similar to D. occipitale (Fischer, 1973) and D. paramicum Munk \& Peris-Felipo, 2013. Dinotrema teutoniaense sp. nov. differs from D. occipitale in having the face 1.2 times as wide as high (1.5 times in D. occipitale), mandible 1.3 times as long as its maximum width (1.5 times in D. occipitale), first flagellar segment 5.5 times as long as its maximum width (3.25 times in D. occipitale), and hind femur 5.0 times as long as its maximum width (4.0 times in D. occipitale). On the other hand, the new species differs from D. paramicum in having the face 1.2 times as wide as high (1.6 times in D. paramicum), first flagellar segment 5.5 times as long as its maximum width (3.0 times in D. paramicum), and hind femur 5.0 times as long as its maximum width (4.15-4.20 times in D. paramicum).

\section{Key for the Nearctic and Neotropical species of Dinotrema}

(According to the key system by Peris-Felipo et al. 2014b).

1. Propodeum entirely or mainly smooth, often with complete or short median carinae, sometimes additionally with short subtransverse carinae emerging from median carina, but far separated from propodeal edges 2

- Propodeum widely or entirely sculptured, often with numerous subtransverse carinae reaching propodeal edges; sometimes additionally with complete longitudinal median carina or large and distinctly delineated areola

2. Propodeum completely smooth, without any median carina ….................................................. I

- Propodeum with short or complete median carinae ................................................................... 3

3. Propodeum with short median carinae, which is sometimes branched posteriorly into two carinae

- Propodeum with a complete median longitudinal carinae following from its base to apex........... III

4. Propodeum with large pentagonal areola ................................................................................ IV

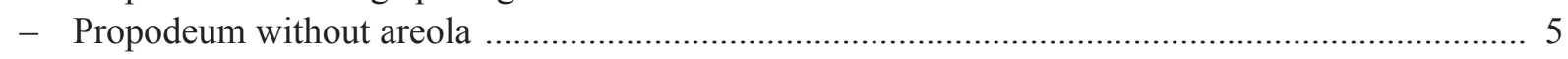

5. Propodeum without complete median longitudinal carina or only with short basal carina ............. V

- Propodeum with complete and distinct median longitudinal carina following from its base to apex

\section{PROPODEUM COMPLETELY SMOOTH}

1. Mesoscutal pit absent. Eye in lateral view 4.8 times as wide as temple medially. Mandible 1.3 times as long as wide. Apical flagellar segment of antenna whitish. Hind femur 4.5 times as long as its maximum width. First metasomal tergite 0.8 times as long as its apical width. Prescutellar depression without lateral carinae. Body length $1.6 \mathrm{~mm}$. U.S.A...... D. armillariae (Fischer, 1969b) 


\section{PROPODEUM WITH SHORT MEDIAN CARINAE, SOMETIMES BRANCHED POSTERIORLY INTO TWO CARINAE}

Until now, no species belonging to group II have been recorded from Neartic and Neotropical regions.

\section{PROPODEUM MAINLY OR WIDELY SMOOTH AND WITH COMPLETE MEDIAN LONGITUDINAL CARINA}

1. First flagellar segment 5.5 times as long as its maximum width (Fig. 8D). Apical flagellar segments paler than middle segments (Fig. 8A, D). Mandible twice as long as its maximum width (Fig. 8C). Mesoscutal pit round and small (Fig. 9A). Paraclypeal fovea long, distinctly surpassing middle distance between clypeus and eye (Fig. 8C). Hind femur 5.0 times as long as its maximum width (Fig. 9D). First metasomal tergite 2.8 times as long as its apical width (Fig. 9C). Body length 1.3$1.4 \mathrm{~mm}$. Brazil D. teutoniaense Peris-Felipo sp. nov.

- First flagellar segment 2.2-3.8 times as long as its maximum width. Apical flagellar segments same colour as middle segments. Mandible 1.2-1.7 times as long as its maximum width. Mesoscutal pit oval or elongate, rather long. Paraclypeal fovea short or medium length, never distinctly continued behind middle distance between clypeus and eye. Hind femur 3.8-4.3 times as long as its maximum width. First metasomal tergite 1.8-2.2 times as long as its apical width

2. First flagellar segment 2.2 times as long as its maximum width. Mandible 1.7 times as long as its maximum width. First metasomal tergite 1.8 times as long as its apical width. Prescutellar depression with lateral carinae. Body length $1.6 \mathrm{~mm}$. U.S.A. D. disstriae (Fischer, 1969)

- First flagellar segment 3.2-3.8 times as long as its maximum width. Mandible 1.2-1.4 times as long as its maximum width. First metasomal tergite 2.0-2.2 times as long as its apical width. Prescutellar depression without lateral carinae

3. Mesosoma in lateral view as long as high. First flagellar segment 3.2 times as long as its maximum width. Paraclypeal fovea short, not reaching middle distance between clypeus and eye. Face 2.2 times as wide as high. Clypeus 3.3 times as wide as high. Body length $1.75 \mathrm{~mm}$. U.S.A.

D. pauperum (Fischer, 1969)
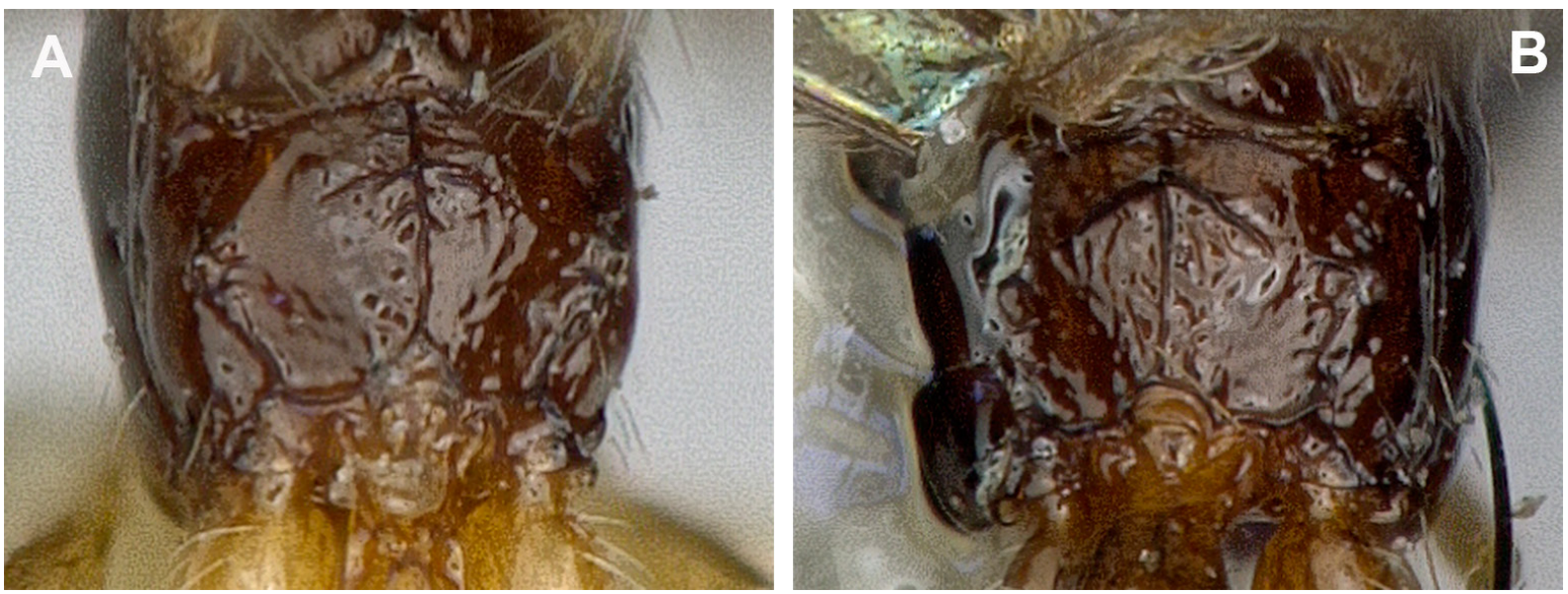

Fig. 10. Sculpture of propodeum. A. Dinotrema angusticorne (Fischer, 1969). B. Dinotrema bucculatricis (Fischer, 1969). 
- Mesosoma in lateral view 1.2-1.3 times as long as high. First flagellar segment 3.5-3.8 times as long as its maximum width. Paraclypeal fovea medium length, reaching middle distance between clypeus and eye. Face 1.8-2.0 times as wide as high. Clypeus 3.0 times as wide as high

4. Eye in lateral view 1.1 times as wide as temple medially. First flagellar segment 3.5 times as long as its maximum width. First metasomal tergite 2.2 times as long as its apical width. Clypeus 2.5 times as wide as high. Body length $2.0 \mathrm{~mm}$. U.S.A.

D. clayensis (Fischer, 1969)

- Eye in lateral view 1.4 times as wide as temple medially. First flagellar segment 3.8 times as long as its maximum width. First metasomal tergite twice as long as its apical width. Clypeus 3.0 times as wide as high

5. Propodeum with short transverse carinae never reaching half surface of propodeum (Fig. 10A). Precoxal suture smooth. Hind femur 4.3 times as long as its maximum width. Body length $1.8 \mathrm{~mm}$. Canada, U.S.A.

D. angusticorne (Fischer, 1969)

- Propodeum with long transverse carinae continued behind half surface of propodeum but not reaching lateral side (Fig. 10B). Precoxal suture crenulate. Hind femur 4.1 times as long as its maximum width. Body length $1.8 \mathrm{~mm}$. Canada, U.S.A.

D. bucculatricis (Fischer, 1969)

\section{PROPODEUM WIDELY OR ENTIRELY SCULPTURED AND WITH DISTINCTLY DELINEATED LARGE AREOLA}

1. Only two teeth of mandible visible in lateral view (Fig. 6A). Mandible 1.7 times as long as its maximum width (Fig. 6A). Apical flagellar segments same colour as middle segments (Fig. 2C). First flagellar segment 2.5-3.0 times as long as its maximum width (Fig. 6C). Eye in lateral view 1.3 times as wide as temple medially (Fig. 6E). First metasomal tergite 1.4 times as long as its apical width (Fig. 7A). Body length 1.6-2.0 mm. Brazil .

D. subbidentatum Peris-Felipo sp. nov.

- Three teeth of mandible visible in lateral view (Fig. 3C). Mandible 1.3 times as long as its maximum width (Fig. 3C). Apical flagellar segments paler than middle segments (Fig. 3D). First flagellar segment 3.5 times as long as its maximum width (Fig. 3D). Eye in lateral view 1.8 times as wide as temple medially (Fig. 3F). First metasomal tergite 3.0 times as long as its apical width (Fig. 4B). Body length $2.0-2.2 \mathrm{~mm}$. Brazil

D. plaumanni Peris-Felipo sp. nov.

\section{PROPODEUM WIDELY OR ENTIRELY SCULPTURED, WITHOUT AREOLA AND MEDIAN LONGITUDINAL CARINA OR ONLY WITH SHORT BASAL CARINA}

1. Mesoscutal pit absent. Hind femur 4.1 times as long as its maximum width. First flagellar segment 3.0 times as long as its maximum width. Paraclypeal fovea short, not reaching middle distance between clypeus and eye. Precoxal suture reaching anterior part of mesopleuron. Posterior mesopleural furrow completely crenulate. Body length $2.2 \mathrm{~mm}$. U.S.A.

D. saileri (Fischer, 1969)

- Mesoscutal pit present, oval. Hind femur 3.4 times as long as its maximum width. First flagellar segment twice as long as its maximum width. Paraclypeal fovea medium sized, reaching middle distance between clypeus and eye. Precoxal suture not reaching anterior part of mesopleuron. Posterior mesopleural furrow crenulate only below. Body length $2.3 \mathrm{~mm}$. U.S.A. D. shannoni (Fischer, 1969)

\section{PROPODEUM MAINLY SCULPTURED AND WITH COMPLETE MEDIAN LONGITUDINAL CARINA}

1. First metasomal tergite 3.1 times as long as its apical width (Fig. 2E). Hind femur 4.4-4.5 times as long as its maximum width (Fig. 1E). Mandible 1.7 times as long as its maximum width (Fig. 1D). 
Head in dorsal view 1.6 times as width as its median length (Fig. 2A). Body length 1.5-2.0 mm. Argentina, Brazil

D. multiareolatum Peris-Felipo sp. nov.

- First metasomal tergite 1.5-2.0 times as long as its apical width. Hind femur 3.5-3.9 times as long as its maximum width. Mandible 1.0-1.3 times as long as its maximum width. Head in dorsal view $1.8-1.9$ times as width as its median length

2. First metasomal tergite 2.0 times as long as its apical width. First flagellar segment 4.0 times as long as its maximum width. Posterior mesopleural furrow completely crenulate. Face 1.8 times as wide as high. Body length $2.9 \mathrm{~mm}$. U.S.A.

D. sylvaticae (Fischer, 1969)

- First metasomal tergite 1.5-1.8 times as long as its apical width. First flagellar segment 3.0 times as long as its maximum width. Posterior mesopleural furrow crenulate only below. Face 1.5 times as wide as high

3. Hind femur 3.5 times as long as its maximum width. First metasomal tergite 1.5 times as long as its apical width. Mandible as long as its maximum width. Clypeus 2.7 times as wide as high. Mesoscutal pit oval. Prescutellar depression without lateral carinae. Body length $1.6 \mathrm{~mm}$. U.S.A.

D. caudatulum (Fischer, 1969)

- Hind femur 3.9 times as long as its maximum width. First metasomal tergite 1.8 times as long as its apical width. Mandible 1.3 times as long as its maximum width. Clypeus 2.1 times as wide as high. Mesoscutal pit elongate. Prescutellar depression with lateral carinae. Body length $2.0 \mathrm{~mm}$. U.S.A.

D. communis (Fischer, 1969)

\section{Discussion}

Dinotrema is one of the largest genera within the subfamily Alysiinae with more than 330 species described worldwide (Peris-Felipo et al. 2014b). Members of this genus were found in most zoogeographical regions but thus far never in South America. This is thus the first record of the genus Dinotrema in the Neotropical region.

The information published in this paper is valuable because of the role of the Aspilota genera group (including Dinotrema) in the regulation of the natural populations of dipterans belonging to the families Phoridae, Anthomyiidae and Platypezidae. In spite of the data presented here, additional studies on this unique region of the Earth is required to increase our knowledge on the composition and diversity of the Dinotrema of the world, as well as to provide the background for the use of these parasitoids in further biological control programs.

\section{Acknowledgements}

We are very thankful to Gavin Broad, Senior Curator and Acting Head of the Insects Division, Natural History Museum of London, for his kindness during our stay in London. We also wish to thank Dominique Zimmermann and Maximilian Fischer, Naturhistorisches Museum Wien, Austria, for their gentleness and the supplied facilities during our stay in Vienna. Finally, we want to thank Isabelle Zürcher-Pfander and Daniel Burckhardt, Naturhistorisches Museum Basel, Switzerland, and Hannes Bauer, Naturhistoriches Museum Bern, Switzerland, for their kindness and help during our use of their photosystems. The present work was supported for the last author by grants given by the Russian Foundation for Basic Research (project No. 16-04-00197) and the Russian state research project No. 01201351189 .

\section{References}

Achterberg C. van 1988. The genera of the Aspilota-group and some descriptions of fungicolous Alysiini from the Netherlands (Hymenoptera: Braconidae: Alysiinae). Zoologische Verhandelingen 247: 1-88. 
Achterberg C. van 1993. Illustrated key to the subfamilies of the Braconidae (Hymenoptera: Ichneumonoidea). Zoologische Verhandelingen Leiden 283: 1-189.

Fischer M. 1969a. (1971) Uber nordamerikanische Arten der Gattungen Orthostigma Ratzeburg und Aspilota Foerster (Hymenoptera, Braconidae, Alysiinae). Acta Entomologica Musei Nationalis Pragae 38 (1969): 81-114.

Fischer M. 1969b. Die nearktischen Arten der Aspilota columbiana-Gruppe und der Aspilota smithiGruppe. Redia 51:187-209.

Fischer M. 1969c. Die nearktischen Aspilota-Arten der pertiolata-Gruppe (Hymenoptera, Braconidae, Alysiinae). Bollettino del Laboratorio di Entomologia Agraria 'Filippo Silvestri' Portici 27: 55-78.

Fischer M. 1969d. Revision der nearktischen Aspilota Arten der signifrons-Gruppe (Hymenoptera, Braconidae, Alysiinae). Sitzungsberichte der Österreichischen Akademie der Wissenschaften Mathematisch. K1. I (178): 243-259.

Fischer M. 1972. Erste Gliederung der palaearktischen Aspilota-Arten (Hymenoptera, Braconidae, Alysiinae). Polskie Pismo Entomology 42 (2): 323-459.

Fischer M. 2003. Ein Beitrag zur Kenntnis der Gattungen Synaldis Foerster und Adelphenaldis Fischer, gen. nov. (Hymenoptera, Braconidae, Alysiinae). Linzer Biologische Beiträge 35 (1): 19-74.

Peris-Felipo F.J. \& Belokobylskij SA. 2013. Dinotrema jimenezi sp. n., a new species of the genus Dinotrema (Hymenoptera: Braconidae: Alysiinae) with only basomedially sculptured propodeum from Spain. Biologia 68 (5): 979-982. http://dx.doi.org/10.2478/s11756-013-0239-6

Peris-Felipo F.J., Belokobylskij S.A. \& Jiménez-Peydró R. 2012. Genus Adelphenaldis Fischer, 2003 (Hymenoptera: Braconidae: Alysiinae) in Spain, with a key to the World species. Annales Zoologici 62(2): 287-296. http://dx.doi.org/10.3161/000345412X652828

Peris-Felipo F.J., Belokobylskij S.A. \& Jiménez-Peydró R. 2013a. Six new Dinotrema species (Hymenoptera, Braconidae) from Spain, with prescutellar pit and medially sculptured propodeum. Zootaxa 3694 (6): 545-564. http://dx.doi.org/10.11646/zootaxa.3694.6.3

Peris-Felipo F.J., Belokobylskij S.A. \& Jiménez-Peydró R. 2013b. New Spanish Dinotrema species with propodeal areola or mainly sculptured propodeum (Hymenoptera, Braconidae, Alysiinae). ZooKeys 297: 43-70. http://dx.doi.org/10.3897/zookeys.297.5228

Peris-Felipo F.J., Belokobylskij S.A. \& Jiménez-Peydró R. 2013c. Dinotrema vitobiasi sp. nov., a new Spanish species of the genus Dinotrema Foerster with only basomedially sculptured propodeum (Hymenoptera, Braconidae, Alysiinae). Zoosystematica Rossica 22 (1): 87-92.

Peris-Felipo F.J., Fischer M. \& Jiménez-Peydró R. 2013d. Five new Dinotrema species with mesoscutal pit and medially sculptured propodeum from Spain (Hymenoptera, Braconidae, Alysiinae). Bulletin of Insectology 66 (1): 59-71.

Peris-Felipo F.J., Broad G.R., Belokobylskij S.A. \& Jiménez-Peydró R. 2014a. Three new Adelphenaldis species (Hymenoptera: Braconidae: Alysiinae) from Africa, with first descriptions of the female of A. subsurrectionis (Fischer) and the male of A. claricornis. African Entomology 22 (3): 561-576. http:// dx.doi.org/10.4001/003.022.0318

Peris-Felipo F.J., Belokobylskij S.A. \& Jiménez-Peydró R. 2014b. Revision of the Western Palaearctic species of the genus Dinotrema Foerster, 1862 (Hymenoptera, Braconidae, Alysiinae). Zootaxa 3885 (1): 1-483. http://dx.doi.org/10.11646/zootaxa.3885.1.1

Peris-Felipo F.J., Belokobylskij S.A., Achterberg C. van \& Pérez-Fernández T. 2014c. Dinotrema cavernicola sp. n. (Hymenoptera, Braconidae, Alysiinae), a new species of the genus Dinotrema 
Foerster from caves of Spain. Journal of Hymenoptera Research 41: 47-56. http://dx.doi.org/10.3897/ $\underline{\text { JHR.41.8606 }}$

Tobias V.I. 2003. Species of the genus Dinotrema Foerster, 1862 (Hymenoptera, Braconidae, Alysiinae) without prescutellar pit and with smooth or only medially sculptured propodeum from Russia and adjacent territories. Entomological Review 83 (3): 279-294.

Tobias V.I. 2004a. Species of the genus Dinotrema Foerster (Hymenoptera, Braconidae, Alysiinae) without prescutellar pit and with a widely sculptured propodeum and short mandibles from Russia and neighboring territories. Entomological Review 84 (2): 216-232.

Tobias V.I. 2004b. Two new species of the braconid genus Dinotrema Foerster (Hymenoptera, Braconidae, Alysiinae) without prescutellar pit. Entomological Review 84 (6): 673-676.

Tobias. V.I. 2006. Palaearctic species of the genus Dinotrema Foerster (Hymenoptera, Braconidae, Alysiinae) with prescutellar pit and long ovipositor. Entomological Review 86 (3): 324-336. http:// dx.doi.org/10.1134/S0013873806030092

Yu D.S., Achterberg C. van \& Horstman K. 2012. Taxapad 2012, Ichneumonoidea 2011. Database on flash-drive. Ottawa, Ontario, Canada.

Manuscript received: 6 October 2015

Manuscript accepted: 3 November 2015

Published on: 7 March 2016

Topic editor: Koen Martens

Desk editor: Natacha Beau

Printed versions of all papers are also deposited in the libraries of the institutes that are members of the EJT consortium: Muséum national d'Histoire naturelle, Paris, France; Botanic Garden Meise, Belgium; Royal Museum for Central Africa, Tervuren, Belgium; Natural History Museum, London, United Kingdom; Royal Belgian Institute of Natural Sciences, Brussels, Belgium; Natural History Museum of Denmark, Copenhagen, Denmark. 